\title{
Debate em fóruns mediados por computador e a reflexão sobre a prática educativa em biologia e ciências.
}

\author{
Paulo Cesar Gomes*
}

\begin{abstract}
Resumo
Este estudo, no âmbito do Estágio Supervisionado em Ciências Biológicas, buscou, através de um fórum virtual mediado por uma plataforma institucional, discutir ideias e crenças de licenciandos sobre o ensino de biologia. A partir de algumas discussões iniciadas em sala de aula, o pesquisador atuou como mediador indicando aspectos que iriam ser abordados pelos licenciandos no fórum. A seguir, serão destacados alguns estudos sobre suas crenças. Entendemos que o Estágio Supervisionado também deve configurar-se num espaço para o debate sobre a atuação docente, sua futura profissão e também acerca do seu processo de formação. É meta promover questionamentos sobre saberes, crenças e concepções acerca de processos de ensino e de aprendizagem e sua relação com a prática educativa.
\end{abstract}

Palavras-chave: Estágio supervisionado. Ciências Biológicas. Fórum virtual. Ensino de biologia.

\section{INTRODUÇÃO}

O Estágio Supervisionado assume um espaço importante para a reflexão sobre as convicções iniciais do tornar-se docente, sobre as teorias da aprendizagem discutidas na formação inicial, sobre os problemas da prática educativa e tantos outros temas. É a partir do contato com a prática em sala de aula e no espaço de diálogo, possibilitado pela disciplina de estágio supervisionado, que os licenciandos podem e devem discutir ideias, validar ou refutar teorias. Essas discussões possibilitam que os futuros professores partilhem, com seus colegas em formação, o impacto dos contatos iniciais com prática em sala de aula. É nesse momento que os estudantes reelaboram suas concepções sobre como ensinar, como aprender e como avaliar. É, para muitos, o momento de testar conhecimentos acumulados no decorrer do curso.

Este estudo, no âmbito do Estágio Supervisionado em Ciências Biológicas, buscou, através de um fórum virtual mediado por uma plataforma institucional, discutir ideias e crenças de licenciandos sobre o ensino de biologia. A partir de algumas discussões iniciadas em sala de 
aula, o pesquisador atuou como mediador indicando aspectos que iriam ser abordados pelos licenciandos no fórum. A seguir, serão destacados alguns estudos sobre suas crenças.

Mendes e Munford (2005) consideram equivocados alguns debates acerca da formação inicial do professor de ciências de âmbito tecnicista. Na visão das autoras, esse debate está circunscrito à visão do professor como mero reprodutor de práticas, transmissor de conhecimentos produzidos por outrem e detentor de um chamado "dom" especial. As consequências, segundo apontam, é a formação de um profissional que limita a sua formação e desenvolvimento exclusivamente ao processo de formação inicial. Ao migrar para a Educação, os graduandos precisam saber que se trata de um ofício que "[...] possui conhecimentos, habilidades, competências e saberes específicos e necessários ao bom desempenho de seus profissionais". (MENDES; MUNFORD, 2005, p.5). Saberes que demandam estudos permanentes e contínua dedicação, com espaço de reflexão sobre certezas e questionamentos sobre saberes e fazeres provenientes da e no âmbito da prática educativa.

Carvalho e Gil-Pérez (2001) sustentam a importância de se investigar o percurso da formação de professores de ciências. Segundo os autores, é preciso permitir possibilidades de expressão aos alunos, mediando atividades que possibilitem uma atitude de reflexão em relação a sua prática educativa. Nesse mesmo sentido, Delizoicov et al (2002) destacaram que os saberes e práticas provenientes da formação inicial são, na maioria das vezes, inapropriados e até insuficientes para a atuação profissional. Algumas peculiaridades sobre a formação do professor de ciências precisam ser revistas e ressignificadas de modo que o desenvolvimento profissional supere a racionalidade técnica. Pensar a formação do professor de biologia e ciências, de acordo com esses autores, é formar pessoas com uma visão mais abrangente, capazes de tomar decisões, refletir sobre seu próprio processo formativo e seu fazer pedagógico.

Um estudo feito por Bejarano e Carvalho (2003) destaca que:

Compreender as crenças ou estrutura de crenças dos professores ou dos futuros professores é uma promissora rota de pesquisa na medida em que crenças influenciam percepções e julgamentos das pessoas. Percepções e julgamentos, por seu lado, afetam comportamentos dos professores em sala de aula. Falar em desenvolvimento profissional do professor é falar do desenvolvimento das crenças desse professor, enfim é falar daquilo que ele acredita

Revista @rquivo Brasileiro de Educação, Belo Horizonte, vol.1, num.2, jul - dez, 2013. 
Debate em fóruns mediados por computador e a reflexão sobre a prática educativa em biologia e ciências.

sobre si mesmo e de seu papel como professor. (BEJARANO; CARVALHO, 2003, p.2).

Na revisão feita por Lopes (2007), percebe-se que existe, segundo a autora, uma dispersão semântica acerca dos descritores que reúnem estudos desta natureza, o que dificulta aproximações e comparações entre resultados de pesquisas. A autora buscou distinguir termos na percepção de diferentes autores e destacou que alguns pesquisadores têm buscado solucionar aspectos dessa dispersão de termos.

No âmbito deste estudo, entendemos que o Estágio Supervisionado também deve configurar-se num espaço para o debate sobre a atuação docente, sua futura profissão e também acerca do seu processo de formação. É meta promover questionamentos sobre saberes, crenças e concepções acerca de processos de ensino e de aprendizagem e sua relação com a prática educativa. Assim, o estágio também "[...] possibilita que sejam trabalhados aspectos indispensáveis à construção da identidade, dos saberes e das posturas específicas ao exercício profissional docente" (PIMENTA; LIMA, 2009, p. 61).

Por outro lado, a ampliação da acessibilidade e mesmo a popularização da internet, o acesso às novas Tecnologias da Comunicação e Informação na Educação (TICE), propiciou aos estudantes da educação superior presencial uma infinidade de recursos e possibilidades adicionais aos processos de ensino-aprendizagem (ALVES; NOVA, 2003).

Segundo Batista e Gobara (2006), apesar das dificuldades de professores e alunos, a utilização dos fóruns on-line não tem garantido a necessária e adequada interação em face ao despreparo docente e suas concepções sobre o alcance da mediação com uso dos fóruns. As autoras apontam, ainda, a necessidade de avançar além do uso dos fóruns como meros repositórios de atividades para o conceito de aprendizagem colaborativa.

O fórum online de um curso a distância, além de ser um
instrumento que funciona como um artefato em um espaço
virtual de aprendizagem possui também uma função
comunicacional: a de um repositório de informações.
Entretanto, o principal papel do fórum deve ser o de servir
como um mediador, um meio preparado pelo professor, para
que ocorram interações entre (o)s professor(es) e os alunos e
entre os próprios alunos para promover a aprendizagem. [...]
Um papel secundário do fórum online é o de permitir que
as mensagens sejam postadas em seu espaço interno;
seus ícones e funções devem possibilitar as operações
dos sujeitos e execução das tarefas solicitadas. Nesse

Revista @rquivo Brasileiro de Educação, Belo Horizonte, vol.1, num.2, jul - dez, 2013. 
caso, ele também tem a função de uma biblioteca, de um comunicador onde se postam e armazenam as mensagens, as discussões, os debates ou objetos para serem utilizados em qualquer momento do curso. (BATISTA; GOBARA, 2006, p. 252, grifos nossos).

Neste estudo, os fóruns assumiram importante papel no registro e discussão acerca das crenças dos estudantes, especialmente porque os alunos poderiam manter ou remover suas postagens. A importância foi grande, porque a ferramenta permitiu romper com as barreiras e distâncias entre escolas. Ao mesmo tempo, permitiu manter um contínuo diálogo com os colegas de turma e com o docente supervisor do estágio.

Soller e Lesgold (2001) apresentaram um modelo de categorização em interações propiciadas a partir de conversações. Os autores buscaram aferir aprendizagens a partir de informações presentes nos diálogos construídos e, alertaram sobre a necessidade da mediação na construção dos conhecimentos pelo grupo.

Ferreira et al. (2003) consideram que os alunos, neste estágio de formação, isto é, de enfrentamento da sala de aula em atividades de estágio curricular supervisionado, passam por um "ritual de passagem". As autoras sustentam que é uma fase crucial, pois é nele que os licenciandos partilham suas experiências e ideias sobre a prática educativa, logo, poder investigar esse período da formação é um momento privilegiado, pois "[...] uma vez que, historicamente, tem ocupado um tempo significativo na formação profissional destes estudantes". (FERREIRA et al., 2003, p. 36).

Vale apontar que, neste estudo, o fórum assumiu uma perspectiva apontada por Morin (2006, p.1), como uma ferramenta de um Ambiente Virtual de Aprendizagem (AVA), previamente planejado e utilizado como apoio ao trabalho docente. A aprendizagem em ambientes chamados digitais sugere que:

El aprendizaje colaborativo no implica necesariamente aprendizaje en grupo, sino la posibilidad de ser capaz de confiar en otras personas para apoyar el propio aprendizaje y proporcionar feedback, como y cuando sea necesario, en el contexto de un entorno no competitivo. (CORREA, 2003, p. 8).

Assim, pode-se pontuar que este estudo surgiu a partir de inquietações deste pesquisador acerca de expressões de uso corrente entre licenciandos do curso de Ciências Biológicas, dos períodos integral 
e noturno. Os estudantes fazem uso indiscriminado de expressões, como por exemplo, "PBL", "aula expositiva dialogada", "método construtivista", entre outras. Neste artigo, vamos nos ater à discussão sobre última expressão.

A palavra "método", de origem grega methodos, é composta por met' e hodos. Met significa: por meio de; meta; através de; e de hodos, que significa via, caminho, cujo significado é "caminho para chegar a um fim". Não há como não relacionar método com procedimento ou com um modo, ou modus de fazer. Quando justaposta, a palavra "construtivista" sugere que existe um caminho definido para chegar a um fim. A justaposição remete a determinada compreensão das orientações construtivistas vigentes, oficialmente, para o ensino de Biologia e Ciências.

\section{PROPOSIÇÕES}

Os objetivos deste estudo foram:

(a) analisar como os estudantes compreendem expressões utilizadas correntemente no meio acadêmico;

(b) possibilitar a interação por meio de fórum online e reflexão acerca da expressão "método construtivista ".

\section{METODOLOGIA}

Participaram deste estudo licenciandos da Universidade Pública Federal do Rio Grande do Norte, campus Natal (RN). Os dados foram analisados considerando a participação dos estudantes em um fórum mantido pela Universidade.

Com o objetivo de estimular discussões sobre a questão do método no ensino de ciências e biologia e debater os inúmeros aspectos provenientes da interação com os estudantes nas salas de aula, foi criado pelo docente um fórum virtual para que os licenciandos, de cinco turmas presenciais do curso de Ciências Biológicas, pudessem interagir.

As cinco turmas participantes eram compostas com 45 alunos, em média, e todos cursavam durante o semestre as disciplinas discriminadas a seguir e respectivas turmas:

(a) Prática de Ensino de Biologia: turmas I e II; 
(b) Prática de Ensino de Ciências Físicas e Biológicas: turmas I e II;

(c) Estágio Supervisionado em Ciências Biológicas I: turma I.

Os estudantes compunham um grupo bastante heterogêneo quanto aos interesses após a formação inicial e, ao total, somavam 118 alunos e alunas.

Todo o acesso e postagens nos fóruns foram feito de modo identificado em uma Plataforma mantida pela própria universidade, mediante uso de um login e senha pessoal. Abaixo foi apresentado o layout do fórum inserido na plataforma.

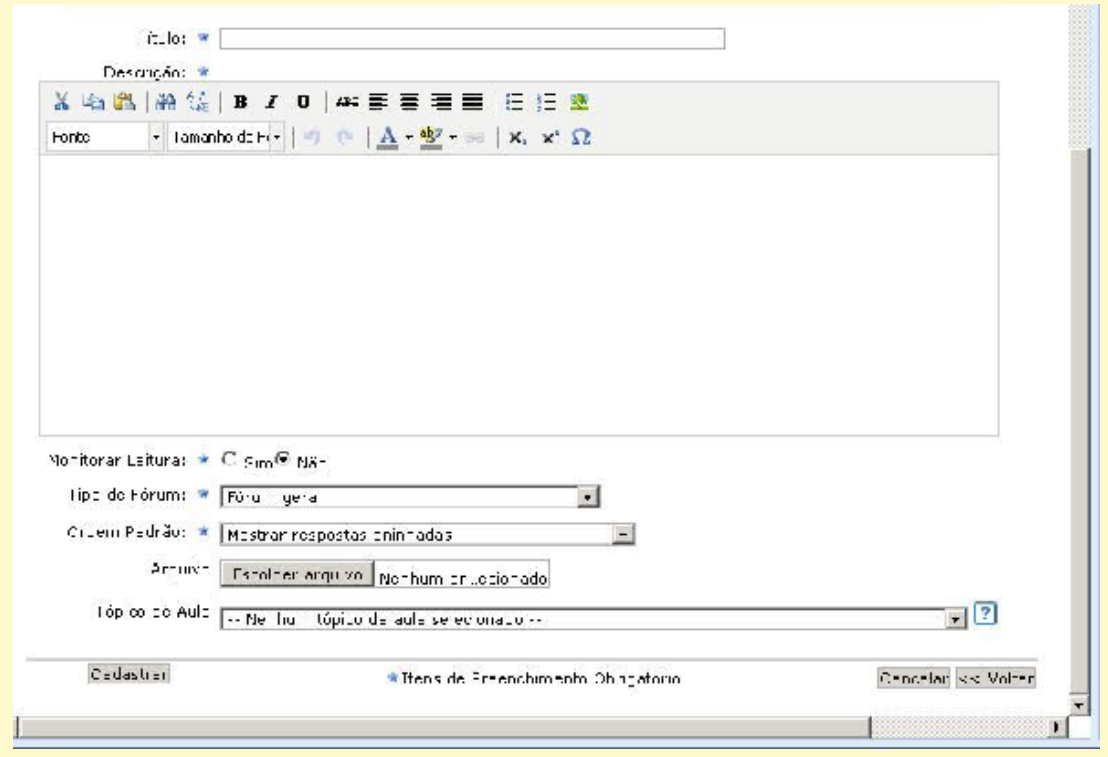

Figura 1 - Layout do fórum mantido pelo SIGAA na UFRN.

Os licenciandos tinham a possibilidade de editar postagens feitas, postar novamente, ou mesmo excluir postagens anteriores. Os depoimentos editados dessas postagens estão distribuídos nos Quadros 1 e 2 deste artigo. Nas publicações aqui transcritas, os licenciandos foram identificados por L1, L2, L3, e, assim, sucessivamente, seguido pela data respectiva, horários e título em negrito.

Dessa forma, os licenciandos foram convidados pelo docente responsável a participar do fórum criado na plataforma com o seguinte texto: 
Debate em fóruns mediados por computador e a reflexão sobre a prática educativa em biologia e ciências.

Docente/Mediador:

Muitos estudantes provenientes de turmas anteriores desta disciplina mencionaram em seus relatórios finais de estágio que eles fizeram uso em sua prática educativa do "Método Construtivista". Discutam, reflitam e argumentem o que vocês compreendem sobre a expressão "método construtivista" na condução das aulas de ciências e biologia.

\section{RESULTADOS E DISCUSSÃO}

Os resultados foram organizados na forma dois quadros com o objetivo de facilitar a visualização dos comentários. As postagens foram editadas para facilitar a análise dos dados.

Quadro 1 - Relato dos licenciandos da turma I, de Ciências Biológicas, acerca da expressão "método construtivista"

\begin{tabular}{|c|c|}
\hline $\begin{array}{c}\text { Participante, } \\
\text { data e } \\
\text { horário }\end{array}$ & Título da postagem e síntese dos comentários inseridos no Fórum 1 \\
\hline $\begin{array}{l}\text { Por L1, em: } \\
\text { 28/02/2011, às } \\
\text { 18:20:02 }\end{array}$ & $\begin{array}{l}\text { Construtivismo - método que estimula o senso crítico: Professor olha } \\
\text { o que eu achei na net.... "Construtivismo - método que estimula o senso } \\
\text { crítico [...] o importante é assistir algumas aulas e observar como os } \\
\text { professores lidam com os alunos. O método construtivista, criado pelo } \\
\text { filósofo Jean Piaget, opta por acompanhar a curiosidade natural da } \\
\text { criança, isto é, ao invés usar um método pré-estabelecido, a escola propõe } \\
\text { temas que interessam naquele momento. Segundo a psicopedagoga Emilene } \\
\text { Beato Correia da Silva, como o próprio nome diz, no construtivismo, as } \\
\text { crianças constroem o conhecimento a partir das suas próprias percepções } \\
\text { [...] Conforme Emilene, que já trabalha há } 15 \text { anos em escolas públicas, } \\
e \text { preciso observar que nem todas as crianças se adaptam ao método } \\
\text { construtivista. Ele é muito bom para aquelas mais desenvolvidas. Mas } \\
\text { há crianças que precisam de estímulos que só a escola tradicional } \\
\text { proporciona", diz. Por esta razão, na opinião da professora o modelo ideal } \\
e \text { mesclar as duas linhas pedagógicas. "O mais correto é misturar os dois } \\
\text { - a criatividade de um método junto com a noção das fórmulas e regras } \\
\text { do outro", finaliza. Por Juliana Lopes. Acesso em: http://vilamulher.terra. } \\
\text { com.br/construtivismo-metodo-que-estimula-o-senso-critico-8-1-55-218. } \\
\text { html }\end{array}$ \\
\hline
\end{tabular}

Revista @rquivo Brasileiro de Educação, Belo Horizonte, vol.1, num.2, jul - dez, 2013. 
Mediador, em 01/03/2011, às 18:48:02
Senso-comum pedagógico??? Sinto a grande dificuldade de uma pessoa que fez jornalismo divulgar artigos sobre temas cientificos. Especialmente provenientes de pesquisas educacionais. Penso que este seja o caso, especialmente, quando a jornalista Lopes fala em... "O método construtivista, criado pelo filósofo Jean Piaget, opta por acompanhar a curiosidade natural da criança..." Vejam, por outro lado, o que dizem os autores da UFMG, Sanchis e Mahfoud (2010) onde alegam que: "Piaget, apesar de ter alguns escritos sobre educação, não foi e não pretendeu ser pedagogo, e não teve, portanto, como interesse, a realização de projetos ou métodos pedagógicos. No entanto, verifica-se que grande parte da produção que tem como fundamento o construtivismo refere-se à educação, e, mais especificamente, à educação formal. Sendo assim, os métodos pedagógicos hoje ditos construtivistas são construções baseadas na teoria formulada por Piaget, principalmente sobre o desenvolvimento infantil (ou em algum tema contido nela) elou em autores que desenvolveram suas pesquisas na mesma linha. O principal interesse de Piaget foi encontrar os mecanismos que possibilitam a construção do conhecimento pelo sujeito, que se constitui nessa construção através de uma interação radical com o objeto do conhecimento.

Leiam o artigo completo em: http://www.reveduc.ufscar.br/index.php/ $\underline{\text { reveduc/article/viewFile/120/86 }}$

Por L2, em

$14 / 04 / 2011$, às

$18: 42: 58$
MÉTODO CONSTRUTIVISTA????? Há sentido em falar sobre a existência de um método construtivista? Não, pois ele é um enfoque educativo que inclui várias teorias com características comuns, neste caso o construtivismo não estaria na categoria de método, mas sim de uma abordagem. Nessa abordagem pode existir vários métodos de ensino de acordo com enfoque teórico do trabalho pedagógico. 
Debate em fóruns mediados por computador e a reflexão sobre a prática educativa em biologia e ciências.

Por L3, $16 / 04 / 2011$ $21: 43: 41$
Método Construtivista??? Professor, achei na internet... "O método construtivista fundamenta-se na escrita, pois acredita que o aluno tem condições de se alfabetizar sem a ajuda de cartilhas e mecanismos que o induzem a decorar, repetir mecanicamente, declamar, transmitir e aprender o que já está acabado. Parte-se da ideia de que a criança, antes mesmo de ser alfabetizada no ambiente escolar, já descobriu como funciona o processo de aprendizado do alfabeto, como, por exemplo, ler do lado esquerdo para o direito. A corrente em questão pressupõe, assim, que se o aprendiz estiver mergulhado em um meio que lhe proporcione e lhe motive a aquisição da alfabetização, ele poderá realizar este intento por si mesmo. Conclui-se dai que o estudante pode construir seu conhecimento, atuando, executando, gestando, edificando este saber a partir do ambiente social em que vive e da relação com os professores. Defende-se que o construtivismo educacional é fruto da união das correntes pedagógicas mais recentes, uma versão estendida destes métodos. Eles compartilham entre si o descontentamento com uma esfera educacional que insiste em preservar o viés ideológico que permeia as escolas tradicionais, as quais continuam recorrendo aos instrumentos do aprendizado mecanizado, que obriga os alunos a decorarem e repetirem como autômatos o conhecimento que lhes é transmitido. A educação, neste método, é tecida em conjunto por alunos e professores, frente aos exercícios da leitura e da escrita, exaustivamente praticadas nas aulas. Assim, mestres e aprendizes atuam juntos na construção do conhecimento, assessorados pela incidência da problemática social mais atual e pelo arsenal de saberes já edificados, patrimônio intransferivel do ser humano. A metodologia construtivista conduz, assim, a uma nova visão de mundo, seja ele o Cosmos ou o universo das interações sociais. Piaget, um dos teóricos mais significativos deste método, acreditava no potencial da criança, no que ela traz em si enquanto herança de sua própria ação e de seu comportamento, o poder nela interiorizado de absorver as informações obtidas do mundo exterior e acomodá-las, isto é, alterar sua forma, para que assim ela possa entender a realidade na qual está inserida. Basicamente, o saber é sempre produzido pelo ato de construção, o qual deve sempre ser estimulado no aluno."

Fonte: http://www.infoescola.com/educacao/construtivismo/

Estes textos tendem ou não a confundir nós leitores?? O que acham???

Por L4, em $17 / 04 / 2011$, às 09:05:04

Construtivismo. Será que no futuro não chamaremos essa ABORDAGEM CONSTRUTIVISTA em MÉTODO CONSTRUTIVISTA mesmo? (risos)... como o próprio artigo diz... um método novo sendo uma junção de pensamentos.

Por L5, em $08 / 05 / 2011$, às $04: 35: 28$.

Re: construtivismo. Galera, sinceramente, não sei se dá pra confiar ou apostar tanto nesse método construtivista...isso é muito lindo, mas quem já começou a dar aula sabe que também é muito dificil. Para os que querem seguir mesmo com a carreira de professor se prepare, porque terá que ralar muito para trabalhar com essa ideia. Eu, como um dos que pretendo seguir essa profissão, já estou me preparando psicologicamente e buscando em vários locais ideias para serem usadas em sala de aula. (risos) E o problema maior...estou dando aula pro $6^{\circ}$ ano...tem que ser um mágico pra ser construtivista com aquela turma que eu estou dando aula. (risos)

Os resultados sugerem que os licenciandos não têm critérios definidos ao selecionar informação de páginas e sítios mantidos na 
internet. Este aspecto é mantido pela escolha dos licenciandos L1 e L3 na busca da expressão "método construtivista" em links de jornais e revistas sem caráter acadêmico. Vale salientar que no caso de L3, apesar de a revista supostamente ter cunho educativo assume pouco ou nenhum valor acadêmico na discussão proposta.

L2 foi quem teve um maior esclarecimento quando diz que o construtivismo se trata de "[...] um enfoque educativo que inclui várias teorias com características comuns [...] não estaria na categoria de método, mas sim de uma abordagem".

O Quadro 1 apontou como L5 compreende a orientação construtivista em relação com sua prática educativa: "E o problema maior é que eu estou dando aula pro $6 .^{\circ}$ ano. Tem que ser um mágico para ser construtivista com aquela turma que eu estou dando aula (risos)" (L5). O aluno não argumenta sobre a postagem de L4 ou sobre as anteriores. Essa não manifestação pode indicar que ele não elaborou uma leitura cuidadosa das postagens anteriores do fórum ou que concorda com o questionamento de L4, isto é, "Será que no futuro não chamaremos essa [sic] ABORDAGEM CONSTRUTIVISTA em MÉTODO CONSTRUTIVISTA mesmo? (risos)" (L4). A postagem de L4, a respeito da postagem feita pelo mediador, pode, também, indicar que ele não realizou a leitura ou, de outro modo, não compreendeu a postagem ou ainda a satirizou.

Quadro 2 - Relato dos licenciandos da turma II de Ciências Biológicas acerca da expressão "método construtivista"

\begin{tabular}{|c|c|}
\hline $\begin{array}{l}\text { Participante, } \\
\text { data e } \\
\text { horário. }\end{array}$ & Título da postagem e síntese dos comentários inseridos no Fórum 2 \\
\hline $\begin{array}{l}\text { Por L6, em } \\
28 / 02 / 2011 \text {, } \\
\text { às 19:30:58 }\end{array}$ & $\begin{array}{l}\text { É... parece que "Método" não é bem a palavra! É engraçado. Nós } \\
\text { recebemos isso, a palavra método, nas aulas, mas eu nunca tinha parado } \\
\text { para pensar. Agora, com o foco nessa palavrinha, ela parece remeter a } \\
\text { uma "receita de bolo", com o passo } 1,2,3 \ldots, \text { e não a um "modo" de } \\
\text { ensino, aprendizagem e avaliação, se é que eu posso chamar assim. Pois é, } \\
\text { então se antes eu tinha dúvidas sobre o que é o Construtivismo, agora eu } \\
\text { tenho mais ainda! Acho que descobri que eu não sei nada sobre, ficou um } \\
\text { mistério em mim. Afinal, quem é você, Construtivismo? }\end{array}$ \\
\hline $\begin{array}{l}\text { Por L7, } \\
\text { 28/02/2011 } \\
20: 34: 29\end{array}$ & $\begin{array}{l}\text { Método Construtivista. Concordo com o L6 no quesito "receita" quando } \\
\text { se diz método construtivista mas acho que caberia mais exatamente o } \\
\text { termo "usar para construir", agora só nos basta saber o que utilizar para } \\
\text { construir, será só o conhecimento e a boa vontade do professor em fazer } \\
\text { aulas interativas que incentivem os alunos a um buscar individual e cheio } \\
\text { de questionamentos??? os incentivos da escola para que nelas estejam o } \\
\text { subsidio para o ponta pé inicial do professor??? Bem, a palavra é bonita } \\
\text { e a ideologia também, mas a receitinha esqueceram de fazer ou deixaram } \\
\text { para que descobríssemos sozinhos mas esse bolo chamado construtivismo } \\
\text { ainda não saiu do cabeçalho, rsrs }\end{array}$ \\
\hline
\end{tabular}

Revista @rquivo Brasileiro de Educação, Belo Horizonte, vol.1, num.2, jul - dez, 2013. 
Debate em fóruns mediados por computador e a reflexão sobre a prática educativa em biologia e ciências.

Por L8, em $02 / 03 / 2011$, às 22:52:22.

Minha Opinião. Eu já havia reparado que não há um "passo a passo" para esse modo de ensino. Só pude perceber quando tive que colocar em prática durante um trabalho de Instrumentação para ensino de Ciências. Não sabia por onde começar, como dar andamento e muito menos terminar a bendita aula. O caracteriza o construtivismo são aquelas perguntinhas (suspeita de erro!) durante toda a aula e a minha maior dificuldade é justamente planejar essas perguntas de tal forma que elas realmente sirvam de degraus para a construção do aprendizado. O construtivismo é simples e complexo ao mesmo tempo. Quem que não sabe toda a teoria bonitona (e básica)? Agora quem danado sabe como colocar em prática??? Seria legal um país com um ensino idealizado desse tipo, mas sei lá, acho que não temos muito tempo pra tá se testando um monte de coisa na escola pública, porque vestibular tá aí e só quem recebe os conteúdos explicadinhos é que tem chance de passar. Acho difícil, alunos que não receberam uma boa base, construir um aprendizado lá na frente, mesmo o professor fazendo uso de coisas do cotidiano. PS.: Eu fiquei digitando essas coisas, mas ao mesmo tempo pensando argumentos contra o que eu mesma escrevi acima: $S$ Pode, em certos momentos, parecer que eu sou contra o construtivismo, mas não sou não! É só confusão no quengo.

Por L9, em

$19 / 04 / 2011$ 20:52:07.

E agora? Quando paguei as famosas "instrumentações para ensino", eu fiquei com a impressão de que o construtivismo era o método (método mesmo) mais eficaz de conduzir uma aula. A teoria sobre método construtivista, realmente, me faz acreditar que este seja o melhor caminho no desenvolvimento de uma aula. Porém, na prática é complicado seguir as ideias construtivistas, uma vez que o ensino está voltado para a aprovação do vestibular. Além disso, eu acredito que a "construção do conhecimento" requer um pouco mais de tempo para ocorrer, diferente de uma aula expositiva na qual os conteúdos são apenas passados aos alunos. Sendo assim eu acredito que poderíamos aplicar conceitos de ambos os modos de ensino (tradicional e construtivista) dependendo do contexto da aula.

Por L10, em 26/04/2011, às 00:39:31.
Utopia. As instrumentações para o ensino de ciências e biologia não passam de utopia. Disciplinas que não mostram a realidade a quem está cursando. Vem com ideias bizarras de elaborar e aplicar aulas para a turma de discentes e torcendo para que estes ajam como estudantes da série abraçada pelo tema e plano de aula. Não funciona. Mas porque estou falando disso agora, né? Evidentemente por causa do "endeusamento" do construtivismo. Grande coisa aplicar construtivismo em uma rede públical pífia de ensino onde o salário é menor que o do professor Raimundo e a escolinha nem é tão engraçada assim. Contra construtivismo? Não sou, mas sou contra a alienação e pregação de valores utópicos. As instrumentações devem se preocupar mais com outras aplicações e ir introduzindo o aluno para a realidade que irá encontrar. Tudo bem, amigos, vocês querem que eu dê uma solução, não é? Não darei!! E não fiquem achando que "se não tem solução não tem problema" porque o problema existe e pelo fato de eu não saber, e nem ter essa missão, dar a solução o assunto está encerrado. Sejamos um pouco mais críticos e não apenas ficar magoados quando um aluno tenta questionar impasses em seminários. 
Por L11, em $03 / 05 / 2011$, às $11: 29: 24$.
[... E É como o L6 falou, a palavra "método" remete a ideia de que temos passo a passo a seguir, e isso não é o que acontece, não existe essa receita, e quando não existe receita, como podemos agir? Arriscar a colocar todos os ingredientes a perder? Ou deixar como está e procurar uma receita verdadeira? No caso do construtivismo, arriscar na minha concepção pode ser como "um tiro no escuro". Quanto às instrumentações, realmente é utópico. Não tive bons resultados quando tive que "apresentar" uma aula, em que os meus colegas de turma tinham que fingir não saber sobre o que eu estava tentando passar, e o pior, era tentar seguir uma linha obrigatória de raciocínio, no meu caso gerar um conflito cognitivo nos meus ditos "alunos". Agora me pergunto, será que isso ajuda, quando temos que pensar em elaborar uma aula? Será que é bom mesmo para o aluno, sei que ele ficando na dúvida vai procurar, questionar, e quando mesmo na dúvida esse aluno permanece quieto, calado? Será que eu fiz bem em gerar esse conflito? Na minha opinião, não. Acredito que se eu elaborar uma aula simples e de fácil acesso aos meus alunos, lógico que não os induzindo ao "método decoreba", farei muito mais por eles do que deixar uma confusão em suas cabecinhas, ainda em formação educacional. E como L10 falou, as instrumentações deveriam, nos dar uma base do quê vamos nos deparar quando entrarmos em sala de aula, sei que não é possível, dizer passo a passo o que vai acontecer, as turmas são diferente, as escolas são diferentes, mas, tentar nos mostrar uma realidade é muito melhor do que tentarmos fingir que não sabemos de nada quando nosso colega está tentando ministrar uma aula. (espero que minhas palavras tenham algum sentido...)

O Quadro 2 aponta que L6 manteve dúvidas em relação à expressão, mas fez algumas inferências e hipóteses sobre o tema. 0 licenciando $\mathrm{L} 7$ fez um comentário sobre as postagens de L6 e concluiu ironicamente que "[...] a palavra é bonita e a ideologia também, mas a receitinha esqueceram de fazer ou deixaram para que descobríssemos sozinhos mas esse bolo chamado construtivismo ainda não saiu do cabeçalho" (L7).

L8 complementa as postagens dos colegas com alguns impasses e questionamentos, mas é dos participantes que melhor resume sua compreensão a respeito das orientações construtivistas no que se refere a seus aspectos metodológicos: "[...] Não sabia por onde começar, como dar andamento e muito menos terminar a bendita aula. O que caracteriza o construtivismo são aquelas perguntinhas [...] O construtivismo é simples e complexo ao mesmo tempo. [...] Agora que danado sabe como colocar em prática? Seria legal um país com um ensino idealizado desse tipo, mas sei lá, acho que não temos muito tempo pra estar testando um monte de coisa na escola pública. PS.: Eu fiquei digitando essas coisas, mas ao mesmo tempo pensando argumentos contra o que eu mesma escrevi acima. Pode, em certos momentos, parecer que eu sou contra o construtivismo, mas não sou não! É só confusão no quengo" (L8).

A escola pública assume, segundo L8, o papel de ser um grande

Revista @rquivo Brasileiro de Educação, Belo Horizonte, vol.1, num.2, jul - dez, 2013. 
laboratório para testar teorias, mas ao mesmo tempo, se defronta com as avaliações externas e o vestibular. L8 restringiu aspectos de como seria uma aula que levasse em consideração os pressupostos construtivistas limitando-se a levantar os conhecimentos prévios dos alunos, ou "aquelas perguntinhas", como principal característica construtivista. Em sua avaliação, afirmou ainda que "Eu já havia reparado que não há um 'passo a passo' para esse modo de ensino" (L8). Destacamos a afirmativa, porque, apesar de os licenciandos terem esse tipo de juízo e, diante das outras assertivas, não fica claro se é feito algum tipo de debate neste sentido em sala de aula.

De qualquer modo, vale ressaltar que é preciso ter melhor compreensão da teoria construtivista, para que se possa planejar e elaborar aulas que estejam mais bem adequadas ao perfil dos aprendizes. E, ao mesmo tempo, permitir que esses estudantes se expressem e aprendam, à medida que interagem com os conteúdos propostos.

L8 ainda faz uma crítica. Para ele, a escola pública tende a ser sempre "um laboratório de experimentação" de práticas pedagógicas, um espaço que praticamente inexiste em escolas voltadas à aprovação em vestibulares.

Os licenciandos L9, L10 e L11 fazem severas críticas à formação inicial e à necessidade de uma melhor compreensão do referencial teórico construtivista e sua relação prática com a realidade das escolas públicas natalenses. L11 faz uma síntese das demais postagens e serviu, no fórum, como um bom exemplo do uso adequado deste espaço para discussão, pois retomou comentários anteriores e elaborou outros novos.

Em relação à temática discutida, é preciso que docentes do ensino superior reflitam sobre como têm ministrado suas aulas e partilhado suas teorias com os licenciandos, especialmente, no uso da linguagem oral, cotidiana da sala de aula. O professor de Biologia e Ciências em formação, como qualquer outro profissional, deve questionar, principalmente, as verdades transmitidas e construídas na forma de certezas, de dogmas ou de teorias indiscutíveis, registradas em postulados ou leis.

\section{CONSIDERAÇÕES FINAIS}

O estágio supervisionado ainda é visto por muitos licenciandos como apenas o cumprimento de uma obrigação burocrática da Universidade ou exigência legal. Por outro lado, o uso de novas 
Tecnologias da Informação e Comunicação pode (e deve) auxiliar o trabalho em sala de aula, pois rompe com a barreira do espaço e do tempo propiciado pela Educação a Distância (EAD).

Esta característica da $E A D$, teve resultado produtivo na condução do estágio supervisionado, pois os estudantes passaram grande parte do tempo nas escolas públicas realizando a regência. A mediação com os licenciandos, através dos fóruns e encontros presenciais esporádicos, permitiu subsidiar algumas discussões que tiveram início em sala de aula e continuaram nos fóruns.

Desse modo, é válido afirmar que os futuros docentes não têm o hábito de utilizar os fóruns mantidos na plataforma do Sistema Integrado de Gestão de Atividades Acadêmicas (SIGAA). Esse fato foi constatado em algumas turmas que sequer se deram ao trabalho de dar continuidade à provocação inicial postada pelo mediador para dar início ao debate. Em relatos pessoais, muitos deles disseram que tinham medo e/ou receio, olhavam apenas e não pensavam em postar nada. Outros estudantes manifestaram-se da seguinte maneira: "Ué? Mas tem que postar nossa opinião? Achei que fosse só para o registro do tema".

O estágio é oportunidade única para o docente em formação e configura um espaço de reflexão sobre a prática educativa e o surgimento de inúmeros conflitos.

De modo positivo, os fóruns online mantidos, pela UFRN, no SIGAA, têm disponibilizado aos docentes e aos alunos uma oportunidade de interação à distância, além de buscar solucionar os muitos impasses ainda não resolvidos em sala de aula.

Os resultados deste estudo remetem a revisão de práticas educativas no ensino superior e mesmo da seleção de conteúdos na proposição de disciplinas pedagógicas do curso de Licenciatura em Ciências Biológicas.

\section{Abstract}

This study was completed within the Supervised Internship in Biological Sciences and aims to discuss ideas and beliefs of future teachers in the area of biology education, through a virtual forum mediated by an institutional platform. The researcher acted as a mediator in some discussions initiated in classroom, indicating themes to be discussed by

Revista @rquivo Brasileiro de Educação, Belo Horizonte, vol.1, num.2, jul - dez, 2013. 
the future teachers in the forum. After that, we highlight some studies about their beliefs. We think that the Supervised Internship for the students should also consist of a space for debate on teaching, their future profession, and on their training process. Our goal is to promote questioning on knowledge, beliefs and conceptions around teaching and learning processes and their relation with the educational practice.

Keywords: Supervised internship. Biological sciences. Virtual forum. Biology education.

\section{REFERÊNCIAS}

ALVES, L.; NOVA, C. (Orgs.). Educação a Distância: uma nova concepção de aprendizado e interatividade. São Paulo: Futura, 2003.

BATISTA, L.J.C.; Aprendizagem colaborativa mediada por computador. Em: Anais do Congresso Internacional de Qualidade em EAD. São Leopoldo: Unisinos, 2005.

BATISTA, E.M.; GOBARA, S.T.; As concepções de professores de um curso a distância sobre o papel do fórum on-line. Em: Revista Brasileira de Estudos Pedagógicos. V. 87, p. 249-261, Brasília, 2006.

BEJARANO, N.R.R.; CARVALHO, A.M.P. Tornando-se professor de ciências: crenças e conflitos. Ciência e Educação, Bauru, v.9, n.1, p. 1-15, 2003.

CARVALHO, A.M.P.; GIL- PÉREZ, D. Formação de professores de ciências: tendências e inovações. 6. ed. São Paulo: Cortez, 2001. 120p.

CORREA, L.M.Z. Aprendizaje colaborativo: una nueva forma de diálogo interpersonal y en red. Contexto Educativo, n. 28. Disponível em: http://contexto-educativo.com.ar/2003/4/nota-02.htm. Acesso em: 04/02/2011.

DELIZOICOV, D.; ANGOTTI, J. A.; PERNAMBUCO, M. M. Ensino de Ciências: fundamentos e métodos. São Paulo: Cortez, 2002. 364p. (Coleção Docência em Formação).

FERREIRA, M.S.; VILELA, M.L.; SELLES, S.E. Formação docente em ciências biológicas: estabelecendo relações entre a prática de ensino e o contexto escolar. In: SELLES, S.E.; FERREIRA, M.S. (Orgs.). Formação docente em ciências: memórias e práticas. Niterói: Eduff, 2003, p. 29-46.

LOPES, M. Gomes, Concepções de licenciandos sobre ensino e 
aprendizagem: análise de uma disciplina de Prática de Ensino de Ciências Biológicas. Dissertação Mestrado. Faculdade de Educação. Universidade Federal de Minas Gerais. Belo Horizonte: UFMG, 2007.

MELLADO, V. The classroom practice of preservice teachers and their conceptions of teaching and learning science. Science Education, v. 82, p. 197-214, 1998.

MENDES, R.; MUNFORD, D. Dialogando saberes: pesquisa e prática de ensino na formação de professores de ciências e biologia. Revista EnsaioPesquisa em educação em ciências, Belo Horizonte, v. 7, dez. 2005. Número especial.

MORIN, J.M.; Pressupostos de mudanças nos cursos presenciais com a educação on-line. Texto apresentado no 11. ${ }^{\circ}$ Congresso Internacional de Educação à Distância. Disponível em: www.eca.uesp.br/porf/moran/ contrib.htm\#gestao. Acesso em 09/07/2011.

PICONEZ, S.C.B.; A prática de ensino e o Estágio Supervisionado. $5^{\text {a }}$ ed. Campinas, SÃO PAULO: Papirus, p. 15 -74, 2000.

SOLLER, W.J.; LESGOLD, A., A machine learning approach to assessing knowledge sharing during collaborative leaning activities. In: International Peg Conference, 10. Tampere. Proccedings Tampere: Tampere University of Tecnology, 2001.

SILVA, M.L.S.F. (org.); Estágio Curricular: contribuições para o rendimento de sua prática. 2. ${ }^{a}$ Ed., Natal: EDUFRN, 2005.

SILVA, L.C.; MIRANDA, M.I.; Estágio Supervisionado e prática de ensino: desafios e possibilidades. Araraquara: Junqueira\&Marin: Belo Horizonte: FAPEMIG, 2008. 